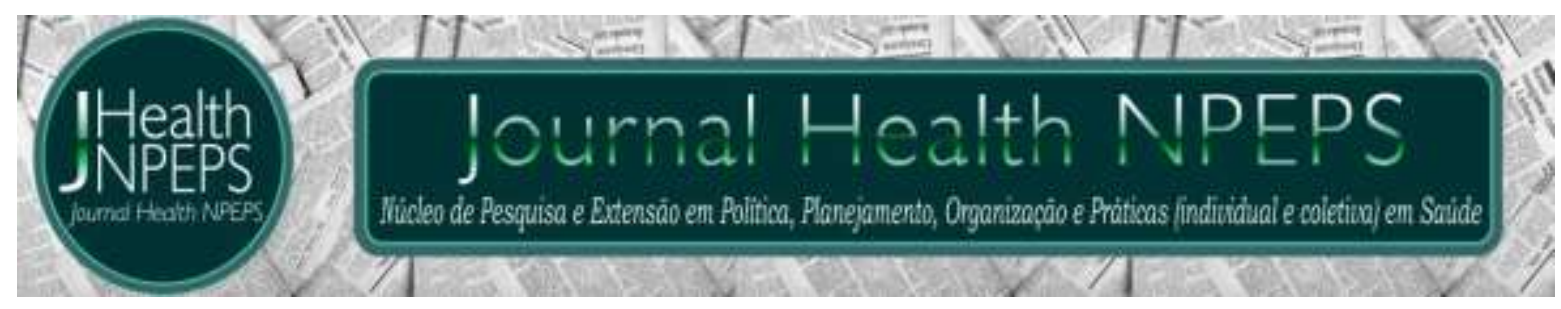

http://dx.doi.org/10.30681/252610103388

ARTIGO ORIGINAL

\title{
Construção e implementação de fichas técnicas de preparação de unidade de alimentação e nutrição
}

\section{Construction and implementation of technical datasheets for preparation of food and nutrition unit}

\section{Construcción e implementación de fichas técnicas de preparación de unidad de alimentación y nutrición}

\section{Igor Gabriel Santiago Pereira1, Letícia Wanzeller Lemos², Kássia Gabrielly Estácio Lemos $^{3}$, Rita de Cássia Coelho de Almeida Akutsu ${ }^{4}$, Raquel Braz Assunção Botelho ${ }^{5}$, Érika Barbosa Camargo ${ }^{6}$}

\section{RESUMO}

Objetivo: construir e implementar fichas técnicas de preparação de uma unidade de alimentação e nutrição militar de Brasília, Distrito Federal. Método: estudo longitudinal e quantitativo. Coleta de dados através de pesagem e observação in loco, construção de fichas técnicas de preparação com o auxílio do software CookGO. Foram realizadas análises nutricionais e análises de indicadores culinários a partir das informações nutricionais do software e das tabelas de composição de alimentos nele inseridas. Resultados: os dados demonstraram a falta de padronização dentro da unidade de alimentação e nutrição. Com isso há um grande desperdício em relação a alguns alimentos e um grande excesso na utilização de outros, gerando grande aporte de alguns nutrientes, como sódio e lipídeos. Conclusão: a ficha técnica de preparação possibilita identificar erros na produção e corrigi-los. Com ela pode-se padronizar preparações,

\footnotetext{
${ }^{1}$ Nutricionista. Especialização em andamento em Nutrição Comportamental. Universidade de Brasília (UnB). Brasília, DF, Brasil. E-mail: igorgsp@yahoo.com.br ORCID ID: https://orcid.org/0000-0002-7434-600X Autor principal Endereço para correspondência: Rua 21 Norte, Lote 3, Edifício Vila Grandino, apartamento 103, Águas Claras, Brasília - DF. CEP 71916000.

${ }^{2}$ Nutricionista. Especialização em andamento em Urgência e Emergência. Universidade de Brasília (UnB). Brasília, DF, Brasil. E-mail: leticiawanzeller@gmail.com ORCID ID: https://orcid.org/0000-0003-0778-4365

${ }^{3}$ Nutricionista. Universidade de Brasília (UnB). Brasília, DF, Brasil. E-mail: kgelemos@gmail.com ORCID ID: https://orcid.org/0000-0001-5709-6275

${ }^{4}$ Nutricionista. Doutora em Ciências da Saúde. Docente Associada da Universidade de Brasília (UnB). Brasília, DF, Brasil. E-mail: rita.akutsu@gmail.com ORCID ID: https://orcid.org/0000-0003-0699-7617

${ }^{5}$ Nutricionista. Doutora em Ciências da Saúde. Docente Adjunta da Universidade de Brasília (UnB). Brasília, DF, Brasil. E-mail: raquelbabotelho@gmail.com ORCID ID: https://orcid.org/0000-0002-0369-287X

${ }^{6}$ Nutricionista. Doutora em Medicina Interna e Terapêutica. FIOCRUZ. Brasília, DF, Brasil. E-mail: erika.barbosacamargo@gmail.com ORCID ID: https://orcid.org/0000-0003-1482-8282
}

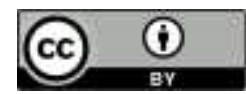

Este artigo está licenciado sob forma de uma licença Creative Commons Atribuição 4.0 Internacional, que permite uso irrestrito, distribuição e reprodução em qualquer meio, desde que a publicação original seja corretamente citada. 
reduzir desperdício, averiguar custo, criar lista de compras, rótulos e, sobretudo, a avaliação nutricional da preparação e sua adequação, o que permite a prevenção de DCNT.

Descritores: Gestão da Qualidade; Serviços de Alimentação; Alimentos.

\section{ABSTRACT}

Objective: to construct and implement technical preparation files for the preparation of a military food and nutrition unit in Brasilia, Distrito Federal. Method: quantitative and longitudinal study. Collection of data through weighing and observation in loco and construction of technical preparation files with the help of CookGO software. Nutritional analyzes and analyzes of culinary indicators were carried out based on the nutritional information of the software and the food composition tables inserted in it. Results: the data demonstrated the lack of standardization within the food and nutrition unit. There was a great waste in relation to some foods and a great excess in the use of others, generating a great contribution of some nutrients, like sodium and lipids. Conclusion: technical preparation files makes it possible to identify errors in production and to correct them. With it, it is possible to standardize preparations, reduce waste, find out cost, create shopping list, labels, and especially the nutritional evaluation of the preparation and its adequacy, which allows the prevention of chronic non-communicable diseases.

Descriptors: Quality Management; Food Services; Food.

\section{RESUMEN}

Objetivo: construir e implementar la estandarización de recetas de un Servicio de Alimentación militar de Brasília, Distrito Federal. Método: estudio longitudinal y cuantitativo. Recolección de datos a través de pesaje y observación in loco, construcción de recetas estandarizadas con la ayuda del software CookGO. Se realizaron análisis nutricionales y análisis de indicadores culinarios a partir de las informaciones nutricionales del software y de las tablas de composición de alimentos en él insertadas. Resultados: los datos demostraron la falta de estandarización dentro de lo Servicio de Alimentación. Con ello hay un gran desperdicio en relación a algunos alimentos y un gran exceso en la utilización de otros, generando un gran aporte de algunos nutrientes, como sodio y lípidos. Conclusión: la receta estandarizada permite identificar errores en la producción y corregirlos. Con ella se pueden estandarizar preparaciones, reducir desperdicio, averiguar costo, crear lista de compras, etiqueta, y sobre todo la evaluación nutricional de la preparación y su adecuación lo que permite la prevención de enfermedades crónicas no transmisibles.

Descriptores: Gestión de la Calidad; Servicios de Alimentación; Alimentos.

\section{INTRODUÇÃO}

\section{A Ficha Técnica de Preparação}

(FTP) pode ser definida como um "instrumento gerencial de apoio operacional, pelo qual se fazem o levantamento dos custos, a ordenação do preparo e o cálculo do valor nutricional da preparação", por esse motivo é ideal que cada Unidade de Alimentação e Nutrição (UAN) tenha suas 
próprias fichas, elaboradas de acordo com a realidade local ${ }^{1,2}$.

A FTP contém os ingredientes, descrição de etapas, tempo total de preparo, per capita, fatores de correção e cocção, composição nutricional da preparação, rendimento, custo dos ingredientes e o número de porções, permitindo fazer controle de gastos, gestão do tempo e escolha das preparações servidas, o que padroniza a receita e assim o produto terá o mesmo padrão de qualidade sempre ${ }^{1,2}$.

Com a FTP, por tanto, pode-se verificar os componentes nutricionais das preparações podendo salientar, por exemplo, que macro e micronutrientes devem ser controlados em virtude de influenciarem no aparecimento de Doenças Crônicas Não Transmissíveis $(\text { DCNT })^{3,4}$.

Desta forma, contribui com a saúde pública, uma vez que auxilia na identificação de pratos nutricionalmente inadequados e na combinação de preparações para que se obtenha um cardápio equilibrado o que certamente levaria a uma melhoria na saúde da população que consome em excesso gorduras, cloreto de sódio, e carboidratos simples, nutrientes estes que têm forte influência na prevalência de doenças como a obesidade, câncer e outras doenças, como as cardíacas ${ }^{2,3}$.

Além disso, o atual cenário epidemiológico deve induzir o profissional nutricionista a um novo raciocínio onde o uso da FTP funciona simultaneamente como ferramenta de diagnóstico que inclui a quantificação nutricional podendo destacar, por exemplo, o teor de sódio presente dentro das preparações que estão contidas dentro de um cardápio, atuando também como ferramenta corretiva visando o equilíbrio nutricional das preparações, além de ser um instrumento de padronização das preparações de um cardápio, por finalmente atuar como parte do processo gerencial das UANs.

Portanto, a FTP proporciona dados de indicadores culinários, permite a elaboração de rótulos, lista de compras, tempo de cocção e tipo de equipamento. É imperativo destacar que combinação de diferentes FTPs pode construir um cardápio equilibrado atendendo as necessidades nutricionais de uma coletividade ${ }^{1,2}$.

Dada a importância do uso das FTP em UAN e da lacuna observada na literatura acerca desta ferramenta sendo encontrado somente seis artigos que tratam deste tema, o objetivo deste 
estudo foi construir e implementar fichas técnicas de preparação de uma unidade de alimentação e nutrição militar de Brasília, Distrito Federal.

\section{MÉTODO}

Trata-se um estudo longitudinal e quantitativo, realizado em UAN de uma instituição militar de Brasília (DF) entre abril e maio de 2017. 0 estudo foi subdividido nas seguintes etapas: coleta de dados; elaboração de FTP; análise nutricional das preparações e análise de indicadores culinários. Todos os dados foram coletados por graduandos de nutrição devidamente treinados e sob a supervisão de um professor nutricionista.

Para a elaboração das FTPs foi realizada a observação direta do almoço por 10 dias de cada manipulador e pesagem dos alimentos in loco enquanto as refeições eram produzidas (15/05/2017 a 25/05/2017). Os dados foram anotados em planilhas próprias para posterior tratamento dos dados. Apesar do estudo ter coletado e analisado todos os macro $\mathrm{e}$ micronutrientes das FTP, neste estudo serão apresentados dados do teor de lipídio e sódio encontrados nas preparações bem como seus indicadores culinários (fatores de correção e fatores de cocção) por serem mais relevantes no contexto da saúde coletiva. A construção das FTP foi por tipo de preparação.

Acompanhou-se a retirada da matéria prima das câmaras frias e pesagem de cada hortaliça separadamente. Foi observado a separação e descarte das partes não comestíveis e inadequadas para o consumo. Após o corte, as hortaliças foram pesadas novamente. Para as entradas cozidas, acompanhou-se o tempo de cocção, e o peso de todos os ingredientes acrescentados. Nova pesagem era realizada após a cocção para se obter o fator de cocção e o rendimento da preparação.

Após a saída dos ingredientes armazenados na câmara fria e no estoque tudo era pesado. $\mathrm{Na}$ área de produção, o manipulador foi observação e todos os passos necessários para o preparo foram anotados. Os ingredientes que não eram usados em sua totalidade, eram pesados e a quantidade não utilizada era debitada do volume total. Além disso, eram determinados os fatores de correção das hortaliças acrescentadas as preparações e estes eram considerados para determinação do peso líquido de tais hortaliças. Todas as preparações, independentemente do método de cocção, eram pesadas ao 
final desta etapa para determinação do rendimento. Foram ainda determinadas a temperatura e o tempo que o alimento era submetido a cocção.

Para as guarnições também acompanhou-se a saída dos ingredientes do estoque seco e câmaras frias com a pesagem de cada item. A semelhança dos pratos principais, os ingredientes que não eram usados em sua totalidade, eram pesados e a quantidade não utilizada era debitada do volume total. Nas guarnições que utilizavam hortaliças e ovos, pesou-se separadamente a parte que seria descartada para o cálculo dos indicadores culinários. Aqui também o método de determinação do rendimento de cada preparação foi semelhante à dos pratos principais. Anotou-se também o tempo de cocção e a temperatura a que o alimento era submetido.

0 arroz (branco e integral) e o feijão são servidos diariamente na UAN, por esta razão coletou-se dados em triplicata em dias alternados por meio da observação do manipulador e pesagem. Para a coleta, verificou-se a quantidade produzida em cada dia por meio da própria embalagem do alimento e os ingredientes adicionados foram pesados e em seguida 0 peso das embalagens debitados. Anotou-se o modo de preparo, o tempo e temperatura que foram submetidos e após a cocção o peso da preparação para determinação do rendimento.

Utilizou-se o software CookGo® para introdução dos dados coletados e o software gerou as fichas com todos os macro e micronutrientes, indicadores culinários, tempo de preparação, modo de preparo, número de porções e rendimento. A análise nutricional completa das FTP foi desenvolvida, sendo calculado os macro e micronutrientes das preparações.

Devido ao volume de tabelas produzidas com as FTP e seus dados quali e quantitativos, neste estudo serão apresentados somente dados mais relevantes no contexto da saúde coletiva, como teor de lipídeos e sódio das preparações.

Para a análise nutricional foram utilizadas as informações nutricionais do software CookGo e das tabelas de composição de alimentos inseridas no software como: United States Department of Agriculture (USDA), do Instituto Brasileiro de Geografia e Estatística (IBGE) e Tabela Brasileira de Composição de Alimentos (TACO).

Para a análise dos indicadores culinários utilizou-se os pesos brutos, líquidos e peso da preparação pronta 
para cálculo dos indicadores culinários usando-se também o software CookGo®.

Devido a grande quantidade de dados e por terem resultados com a mesma justificativa, fez-se uma tabela (tabela 2) comparando os resultados, como um alto Fcy, com a referência e a sua justificativa.

\section{RESULTADOS}

Dos 65 alimentos utilizados nas preparações das entradas, $18,5 \%(n=12)$ deles têm com FC maior que a referência. Os valores de sódio das entradas não apresentaram diferenças significativas em relação a referência, pois as hortaliças foram apenas higienizadas, descascadas e cortadas. Não adicionou-se sal ou outros ingredientes, assim como as hortaliças da referência utilizada (IBGE).

Portanto, os valores de sódio e lipídio são intrínsecos aos alimentos.

Em relação aos pratos principais, observou-se que $60 \% \quad(n=12)$ deles apresentaram uma maior quantidade de sódio quando comparados com a referência. Quando comparados em relação a quantidade de lipídeos, 65\% $(n=13)$ apresentaram valores maiores do que os citados nas referências. Considerando as referências em relação ao fator de cocção, $15 \% \quad(n=3)$ das preparações apresentaram fatores inferiores, $10 \% \quad(n=2) \quad$ apresentaram fatores superiores.

0 ingrediente tempero é preparado na UAN e possui sal, alho, cebola e óleo. Acerca dos Acompanhamentos, somente o feijão teve $12,7 \%$ mais sódio que a referência, enquanto nenhum apresentou mais lipídeos. Sobre o fator de cocção, 2 das 3 preparações tiveram um valor $28,3 \%$ maior que a referência, em média. 
Tabela 1 - Teor de lipídio, sódio e indicadores culinários das entradas servidas em uma unidade de alimentação militar por 100g da preparação. Maio de 2017. Brasília, DF, Brasil.

Preparação

Mix de Folhas

Beterraba Ralada

Vinagrete

Caponata de Berinjela

Mix de Acelga e alface

Tomate com Azeitonas

Cenoura Ralada

Alface Lisa

Alface com abacaxi

Chuchu cozido com ovos

Abobrinha cozida com tomate

Tomate meia lua

Salada de macarrão

Alface

Mix de folhas

Beterraba cozida

Tomate em fatias com azeitona

\begin{tabular}{|c|c|c|}
\hline Alimento & FC obtido & FC referênci \\
\hline Alface Lisa & 1,12 & $1,09-1,33$ \\
\hline Repolho & 1,31 & 1,72 \\
\hline Acelga & 1,40 & $1,54-1,66$ \\
\hline Beterraba & 1,08 & $1,61-1,88$ \\
\hline Tomate & 1,17 & 1,25 \\
\hline Cebola & 1,31 & $1,032,44$ \\
\hline Pimentão & 1,21 & 1,26 \\
\hline Berinjela & 1,04 & $1,04-1,08$ \\
\hline Tomate & 1,04 & 1,25 \\
\hline Pimentão Verde & 1,25 & 1,26 \\
\hline Acelga & 1,38 & $1,54-1,66$ \\
\hline Alface & 1,40 & $1,09-1,33$ \\
\hline Tomate & 1,05 & 1,25 \\
\hline Azeitona & 1,00 & 1,00 \\
\hline Cenoura & 1,16 & 1,17 \\
\hline Alface Lisa & 1,49 & $1,09-1,33$ \\
\hline Alface lisa & 1,50 & $1,09-1,33$ \\
\hline Abacaxi & 1,90 & 1,89 \\
\hline Chuchu & 1,01 & 1,47 \\
\hline Ovos & 1,12 & 1,12 \\
\hline Açúcar & 1,00 & 1,00 \\
\hline Abobrinha & 1,05 & $1,33-1,38$ \\
\hline Tomate & 1,04 & 1,25 \\
\hline Tomate & 1,12 & 1,25 \\
\hline Macarrão & 1,00 & - \\
\hline Ervilha & 1,00 & 1,00 \\
\hline Milho & 1,00 & 1,00 \\
\hline Presunto & 1,00 & 1,00 \\
\hline Óleo & 1,00 & 1,00 \\
\hline Azeite & 1,00 & 1,00 \\
\hline Sal & 1,00 & 1,00 \\
\hline Alface americana & 1,49 & $1,09-1,33$ \\
\hline Alface lisa & 1,50 & $1,09-1,33$ \\
\hline Acelga & 1,40 & $1,54-1,66$ \\
\hline Beterraba & 1,08 & $1,61-1,88$ \\
\hline Tomate & 1,11 & 1,25 \\
\hline
\end{tabular}

LIP (g) LIP (g)

$\mathrm{Na}(\mathrm{mg})$

obtido

-

0,12

0,10

0,17

$1,15 \quad 6,21$

$\mathrm{Na}(\mathrm{mg})$
obtido

$\mathrm{Na}(\mathrm{mg})$

referência

Fcy obtido

3,60

-

78,00

$\begin{array}{lll}6,21 & 86,00 & 1300,00\end{array}$

0,58

$-$

157,80

1,05

0,20

8,00

0,55

$-$

0,18

0,24

0,10

0,15

4,20

0,13

1,27

$-$

0,18

$-$

5,00

$0,20 \quad 0,20$

5,20

2,21

$-$

154,68

69,00

28,00

14,45

1,27

0,90

eferência

-

.

$\begin{array}{ll}0,10 & 0,15 \\ 0,12 & - \\ 0,10 & 0,17 \\ 0,55 & -\end{array}$

4,20
2,44
10,00
45,00

28,00

78,00

0,96

0,90 


\begin{tabular}{|c|c|c|c|c|c|c|c|c|c|}
\hline & Azeitona & 1,00 & 1,00 & & & & & & \\
\hline Alface em tiras & Alface crespa & 1,50 & 1,47 & 0,10 & 0,15 & 4,20 & 28,00 & & - \\
\hline Vinagrete & Tomate & 1,16 & 1,25 & 1,15 & 6,21 & 86,00 & 1300,00 & & - \\
\hline \multirow[t]{5}{*}{ Completa } & Cebola & 1,29 & $1,03-2,44$ & & & & & & \\
\hline & Pimentão & 1,20 & 1,26 & & & & & & \\
\hline & Sal & 1,00 & 1,00 & & & & & & \\
\hline & Vinagre & 1,00 & 1,00 & & & & & & \\
\hline & Azeite & 1,00 & 1,00 & & & & & & \\
\hline \multirow{4}{*}{$\begin{array}{l}\text { Brócolis, couve-flor e berinjela } \\
\text { cozidos }\end{array}$} & Brócolis & 2,02 & 2,12 & 1,40 & - & 0,13 & - & 1,65 & 0,95 \\
\hline & Couve-flor & 2,20 & $2,22-2,46$ & & & & & & \\
\hline & Berinjela & 1,05 & $1,04-1,8$ & & & & & & \\
\hline & Cebolinha & 1,15 & 1,18 & & & & & & \\
\hline Rúcula com tomate seco & $\begin{array}{l}\text { Rúcula } \\
\text { Tomate Seco }\end{array}$ & 1,00 & & & & & & - & - \\
\hline \multirow[t]{3}{*}{ Grão de bico à vinagrete } & Grão de bico & & 1,00 & 3,20 & - & 33,60 & - & 1,28 & 1,28 \\
\hline & Cebola & 1,39 & $1,10-1,4$ & & & & & & \\
\hline & Pimentão & 1,19 & 1,26 & & & & & & \\
\hline \multirow[t]{2}{*}{ Cenoura ralada com milho verde } & Cenoura & 1,29 & 1,17 & 0,30 & - & 50,00 & - & - & - \\
\hline & Milho Verde & 1,00 & 1,00 & & & & & & \\
\hline \multirow[t]{2}{*}{ Repolho com abacaxi } & Repolho & - & - & - & - & - & - & - & - \\
\hline & Abacaxi & & & & & & & & \\
\hline \multirow[t]{4}{*}{ Tabule } & Triguilho & 1,00 & 1,00 & 1,75 & - & 87,00 & - & - & - \\
\hline & Tomate & 1,40 & 1,25 & & & & & & \\
\hline & Cebola & 1,10 & 1,03 & & & & & & \\
\hline & Pimentão & 1,19 & 1,26 & & & & & & \\
\hline \multirow[t]{2}{*}{ Tomate com azeitonas } & Tomate & 1,40 & 1,25 & 0,55 & - & 45,00 & - & - & - \\
\hline & Azeitonas & 1,21 & 1,00 & & & & & & \\
\hline \multirow[t]{2}{*}{ Alface com agrião } & Alface & 1,05 & 1,31 & & & & & - & - \\
\hline & Agrião & 1,00 & 1,78 & & & & & & \\
\hline \multirow{2}{*}{ Brócolis com couve-flor } & Brócolis & 2,02 & 2,12 & - & - & - & - & - & - \\
\hline & Couve-flor & 2,20 & $2,22-2,46$ & & & & & & \\
\hline
\end{tabular}

Legenda: FC: Fator de Correção, FCc: Fator de Cocção. 
Tabela 2 - Indicadores culinários e dados nutricionais relevantes dos pratos principais. Maio de 2017. Brasília, DF, Brasil.

\begin{tabular}{|c|c|c|c|c|c|c|}
\hline $\begin{array}{lr}\text { Alto teor } & \text { de } \\
\text { sódio } & \text { devido } \\
\text { adição } & \text { de } \\
\text { temperos } & \\
\text { salgados }\end{array}$ & $\begin{array}{l}\text { Alto teor } \\
\text { lipídico devido } \\
\text { à não retirada } \\
\text { da capa de } \\
\text { gordura/pele }\end{array}$ & $\begin{array}{lr}\text { Alto } & \text { teor } \\
\text { lipídico devido } \\
\text { adição de } \\
\text { ingredientes } \\
\text { ricos nestes }\end{array}$ & $\begin{array}{lr}\text { Menor } & \\
\text { potencial de } \\
\text { FCy devido } \\
\text { retirada do } \\
\text { molho } \\
\text { cozimento de }\end{array}$ & $\begin{array}{l}\text { Menor } \\
\text { potencial } \\
\text { devido ao } \\
\text { incorreto } \\
\text { forno } \\
\text { combinado }\end{array}$ & $\begin{array}{r}\text { FCy } \\
\text { uso } \\
\text { do }\end{array}$ & $\begin{array}{l}\text { Menor } \\
\text { potencial } \\
\text { devido } \\
\text { cozimento } \\
\text { excessivo }\end{array}$ \\
\hline
\end{tabular}

de Frango

Filé ao Molho -

Ferrugem

Strogonoff de $X$

Frango

Picanha ao $\mathrm{X}$

Molho

de

Mostarda

Espetinho de -

Filé Mignon

Coxa

e $X$

ao

Sobrecoxa

Curry

Moqueca de $X$

peixe

Frango xadrez -

Arroz

carreteiro

Frango assado $X$

ao creme de

cebola

Maminha $\quad X$

assada ao alho

frito

Coxa

sobrecoxa

Mineira

Maminha ao

Molho

Ferrugem

Fricassê

Frango

ao $x$

à $x$

de -

Journal Health NPEPS. 2019 jan-jun; 4(1):210-227.
Menor

potencial

devido

descongelamen

to

temperatura

inadequada

$\mathrm{X}$

$x$

$x$

Alto FCy devido Maior

devido

retirada

excessiva no

processo de

limpeza da

peça

X 


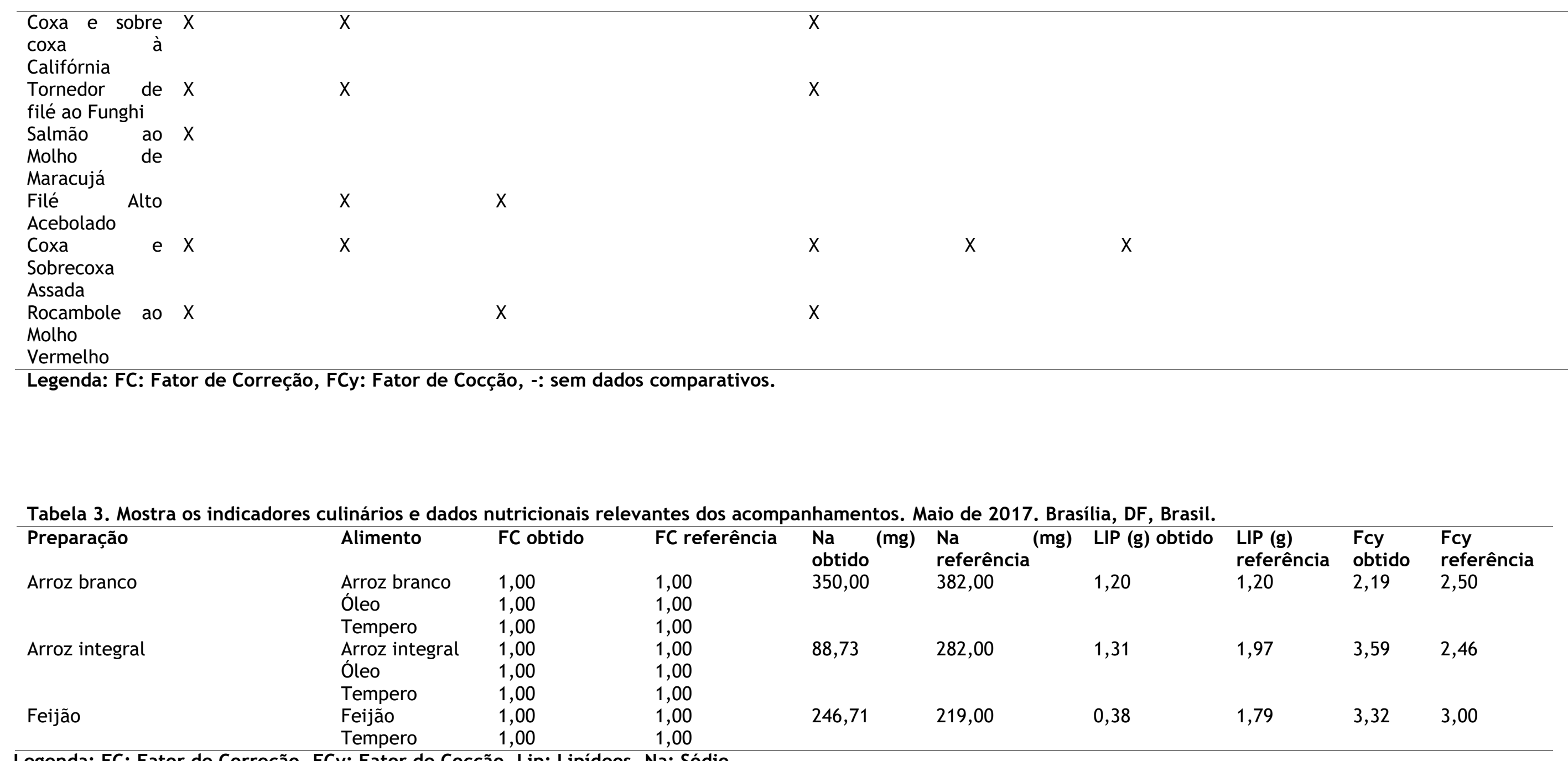

Legenda: FC: Fator de Correção, FCy: Fator de Cocção, Lip: Lipídeos, Na: Sódio. 


\section{DISCUSSÃO}

Em relação às entradas, avaliouse principalmente $0 \quad F C$ e FCy, indicadores importantes para avaliar o desperdício e rendimento respectivamente $^{5}$. A FTP é o instrumento que possibilita a visão destes fatores e assim, possibilita minimizar as perdas desses alimentos tão importantes para a saúde humana ${ }^{6}$.

Devido a manipulação inadequada no pré-preparo dos alimentos ocorre aumento das perdas ${ }^{7}$, como a alface lisa que na preparação mix de acelga e alface apresentou FC de $5,2 \%$ maior que a referência e na preparação alface com abacaxi apresentou FC 12,78\% maior. Sendo a má qualidade do alimento um fator que também contribui, pois maiores retiradas são necessárias.

Foi observado também na UAN uma alta rotatividade dos manipuladores o que geram diferentes FC para o mesmo alimento. Por exemplo, a alface lisa possui 4 valores diferentes, tendo como média 1,37 e o tomate que está presente 17 vezes no cardápio, apresenta 11 valores diferentes para o FC. Ademais o equipamento utilizado também contribui com diferentes resultados quando não possui manutenção adequada, como o visto para a cenoura ralada que apresentou FC diferentes nas duas vezes que foi feita.

Percebe-se com isso que a manipulação ${ }^{7}, \quad$ maquinário $e \quad a$ qualidade do alimento são causas importantes para o que é perdido do alimento, podendo ter grandes variações por contas desses aspectos.

Em relação ao $\mathrm{FCy}$, comparado a referência, a abobrinha apresentou FCy $13,97 \%$ maior que a referência ${ }^{8}$, isso deve-se ao fato de ter sido cozida com casca o que prejudica a absorção de água. Já a beterraba obteve FCy maior que a referência $(6,66 \%)$, podendo ser explicado pelo binômio tempotemperatura que ocasiona aumento da absorção de água 5 .

Nos pratos principais, acerca do alto teor de sódio, as preparações coxa e sobrecoxa ao curry e picanha ao molho de mostarda apresentaram teor de sódio acima da referência descrita pelo IBGE. Esse alto teor de sódio se dá ao uso de produtos industrializados como a mostarda que de acordo com os dados do IBGE possui $1135 \mathrm{mg}$ de sódio a cada sem gramas de alimento, além da utilização do tempero da produção que possui como base o sal ${ }^{9}$. Um estudo de 2013 aponta que a ingestão de sódio no Brasil chega a aproximadamente $4500 \mathrm{mg} / \mathrm{dia}$, sendo que a recomendação pelo Instituto de Medicina Norte-Americano é de no máximo $2300 \mathrm{mg} / \mathrm{dia}^{20}$. Logo podemos 
justificar altas concentrações desses nutrientes devido à alta quantidade de temperos industrializados, como shoyu, mostarda, e molho inglês adicionado às preparações ${ }^{9}$. Alguns desses acréscimos podem ser evitados, como no caso do shoyu e do molho inglês que são adicionados para dar cor à preparação, sendo que isso poderia ser facilmente contornado com temperos naturais ou modo de cocção diferentes. Outro fator que auxilia nessa alta concentração de sódio são os baixos fatores de cocção, pois isso faz com que a carne perca uma maior quantidade de líquidos e aumente a concentração de sódio presente no tempero utilizado.

0 alto teor lipídico comparado à referência também foi bastante evidenciado, isso devido à não retirada de capa de gordura e pele das carnes, além da adição de outros ingredientes ricos em gordura. Nas preparações à base de coxa e sobrecoxa assada, maminha e picanha, estas não tem sua gordura retirada completamente, como a pele do frango e capa de gordura da carne, o que contribui para o lipídio aumentado. ${ }^{10}$. Por exemplo a coxa e sobrecoxa ao curry e picanha ao molho de mostarda, que apresentaram um alto de lipídeos maior em 106\% em média.

As carnes são um dos alimentos que mais contribuem para a ingestão de gorduras, e quando consumidas em restaurantes impactam ainda mais a ingestão desses macronutrientes ${ }^{11}$, pois em altas temperaturas os lipídeos são liberados nas preparações e as tornam ricas neste nutriente ${ }^{12}$, sem contar também com a utilização de grandes quantidades de óleo para chapear as carnes $^{13}$. Fora dessa curva, temos o arroz carreteiro que obteve $68 \%$ menos sódio e $75 \%$ menos lipídio que a referência, isso pode ter ocorrido visto que usaram patinho e nas receitas originais usam carnes mais salgadas e gordas, como charque ${ }^{10}$.

Já o menor potencial de ter uma fator de cocção maior é devido ao descarte de molho, como no strogonoff de frango e na coxa e sobrecoxa ao curry e a picanha ao molho de mostarda, que apresentaram fator de cocção menor que os indicados pela referência, $15 \mathrm{e}$ $4,3 \%$ respectivamente ${ }^{14}$. Esse desperdício se dá ao grande revezamento de funcionários, como não há padronização, cada um executa a sua forma, mostrando mais uma vez a relevância de FTP para a padronização na execução e o controle de desperdícios ${ }^{1}$. A coxa e sobrecoxa assada, assim como outras preparações, apresentaram um menor fator de cocção devido à três fatores: perda de líquidos no descongelamento ${ }^{15}$, forno combinado sem controle de umidade ${ }^{16}$ e tempo de cozimento maior que o necessário ${ }^{5}$. 
Já o salmão ao molho de maracujá apresentou um fator de cocção $21 \%$ maior que o esperado pois, este, além de assar por pouco tempo no forno combinado, foi assado com controle de umidade, o que o fez perder pouco líquido durante seu cozimento ${ }^{16}$. Todas as preparações, exceto o salmão ao molho de maracujá, apresentaram fator de cocção menor que 1 , o que significa que tiveram perda de massa. Isso ocorre pois no calor que foram submetidos (calor seco), há à retração das fibras musculares devido a coagulação das proteínas, fusão das gorduras e perda de água ${ }^{12}$.

Quando usado o forno combinado sem esta função, a preparação não extrai os benefícios desses, como: assar, fritar, grelhar, gratinar, aquecer mantendo a umidade, cozinhar em banho-maria e a vapor. O uso desse modo de preparo diminui o desperdício e não precisa da utilização de gordura. Por meio da circulação combinada de ar quente e vapor, o alimento preparado no forno combinado recebe um aquecimento homogêneo, garantindo uma cocção uniforme e preservando as características sensoriais e nutricionais ${ }^{16}$. Todos esses problemas citados nas preparações acima podem ser sanados com o auxílio de FTPs. Na FTP há a descrição de como e por quanto tempo descongelar, temperatura, umidade e tempo de cozimento a serem atualizados no equipamento, há uma descrição total para a execução da tarefa, minimizando todos esses erros ${ }^{1}$. O espetinho de filé mignon apresentou fator de cocção $13 \%$ maior que o referenciado, podendo ser atribuído ao tempo de cocção do alimento, retardando o goteio e a saída de líquido da carne ${ }^{5}$.

Acerca do fator de correção, observou-se a variação em relação aos fatores de correção das hortaliças utilizadas na preparação, isso se dá ao não treinamento e variação de manipuladores dentro da unidade, evidenciando a necessidade de uma padronização para a excelência do serviço ${ }^{1}$. Por exemplo, na preparação coxa e sobrecoxa ao curry a sobrecoxa obteve fator de correção 6,8\% menor que aos dados da referência, pelo fato da mesma não ser limpa, os pedaços do frango são coccionados com pele, o tomate e o pimentão desta preparação apresentaram fatores de correção abaixo do referenciado 11,6 e $10,8 \%$ respectivamente, porém a cebola obteve um fator de correção $30,7 \%$ acima do referenciado.

Na preparação picanha ao molho de mostarda a cebola apresentou valor de correção $10,5 \%$ maior que o esperado, já a picanha apresentou fator de correção próximo ao da referência, já 
que o corte não possui limpeza. No strogonoff de frango a cebola apresentou fator de correção 9,6 \% maior que o da referência da preparação, e o frango apresentou fator de correção 48,3\% menor por não apresentar pele nem osso. O espetinho de filé obteve um fator de correção $17,5 \%$ mais alto que 0 esperado, houve a limpeza peça e o corte, aumentando assim esse fator. 0 filé apresentou fator de correção dentro da linha de referência, a cenoura obteve um fator de correção 7,6 \% menor, que pode estar relacionado ao equipamento utilizado e o tempo, o descascador possui uma lixa que está desgastada, a cenoura não ficou tempo suficiente dentro do descascador, e com isso seu fator de correção apresentado foi abaixo da referência, a cebola obteve um fator de correção $10,5 \%$ mais alto que o esperado.

No escondidinho de frango o peito de frango apresentou fator de correção 49,3\% menor que o esperado por conta da pele e do osso não estarem presentes no frango da preparação, a batata obteve fator de correção 2,8\% menor que o referenciado, por ser descascada no mesmo equipamento que a cenoura. A preparações que apresentaram fator de correção maior que a referência podem ser explicados por falta de treinamento dos manipuladores, visto que há alta rotatividade de funções e além disso, não utilizam sempre o mesmo utensílio, o que estiver disponível que é usado, assim, pode-se ter uma faca mais precisa que outras gerando as diferenças observadas ${ }^{2}$.

Em relação as guarnições, um terço $(n=3)$ das guarnições apresentou quantidade de sódio maior que a referência, enquanto 22,2\% (2 de 9) apresentaram maior quantidade de lipídeos. Apresentaram sódio maior que a referência, o purê misto de batata e cenoura pelo uso do leite em pó que de acordo com os dados do IBGE possui $320 \mathrm{mg}$ de sódio a cada cem gramas de alimento, além da utilização do tempero da produção que possui como base o sal. E o pirão de ovos devido ao molho de tomate industrializado. Os ingredientes processados tendem a aumentar o sódio da refeição e seu excesso está associado a DCNT, como hipertensão $\operatorname{arterial}^{17}$, sendo a FTP a ferramenta que auxilia nesta análise e possibilita mudanças na preparação e consequente benefícios à saúde populacional.

O nhoque à bolonhesa também apresentou sódio maior, mas lipídio menor que a referência, podendo ser explicado pelo uso de ketchup no nhoque da unidade que contribui com sódio total da preparação e pelo uso de carne magra nesta preparação. Já a farofa rica possuiu lipídio consideravelmente 
elevado devido à grande quantidade de manteiga utilizada para conferir mais sabor e textura mais úmida para agradar os comensais e pela falta de padronização, uma vez que na UAN avaliada não possuía FTPs ${ }^{5}$.

Em relação ao $\mathrm{FC}$ diferentes da literatura para os alimentos das guarnições, decorrem da qualidade do ingrediente, não descascamento de algumas hortaliças e treinamento do manipulador. Quanto ao FCy, o purê de mandioca por ser rico em amido apresentou o FCy maior que 1 , pois quando aquecido em água ele se gelatiniza $\mathrm{e}$ se expande consideravelmente - de 10 a $20 \%{ }^{18}$. A abobrinha refogada com queijo foi maior que a referência $(6,45 \%)$ e os legumes salteados menor $(4,16 \%)$ em decorrência do tempo de cocção.

Em relação ao fator de cocção, o arroz branco apresentou, em média, fator de cocção $12 \%$ menor que o da referência, isso se dá pela maior formação de vapor que acontece na cocção em caldeiras, diminuindo a absorção de líquido por parte da preparação, porém a preparação se encontra adequada. Isso deixa o arroz branco abaixo de 2 entre 3 referências utilizadas, sendo este de 2,19 contra 2,70, 2,50 e 1,9712. O arroz integral, em média, obteve fator de cocção $46 \%$ maior o que o da referência, podendo ter como causa uma maior quantidade de fibras do produto utilizado ou um maior tempo de cocção e com isso uma maior absorção de água, chegando à triplicar relacionada ao volume inicial ${ }^{13}$.

O feijão obteve fator de cocção $11 \%$ mais alto, em média, que o da literatura, podendo ser justificado pelo remolho, que aumenta a retenção de água ${ }^{5,12}$ a que é submetido que acontece desde o dia anterior a sua preparação, aumentando seu volume e diminuindo assim o tempo de cocção e a evaporação de água além do abrandamento de fibras ${ }^{19}$.

Acerca da quantidade de sódio e de lipídeos, em média, o arroz da unidade é aproximadamente 25\% menor em sódio referente à do IBGE $^{9}$, e os lipídeos encontram-se em maior proporção em comparação à referência, sendo este $22 \%$ maior. Isso ocorre pela adição de três garrafas de óleo por caldeira, sendo que essa adição não é necessária para que haja uma cocção eficiente. Acerca do arroz integral, este é, em média, $68,5 \%$ menor em sódio devido à pouca adição do tempero pronto, enquanto o lipídeo é $33,5 \%$ menor devido ao alto fator de cocção que diminuiu a concentração de óleo de soja na preparação, assim como de sódio.

Quanto ao feijão, em média, esta relação encontra-se em menor 
quantidade de sódio por 100 gramas de peso cozido, sendo de 259 miligramas contra 224 do $\mathrm{IBGE}^{9}$. Os lipídeos encontram-se aproximadamente $80 \%$ menores no feijão avaliado com relação ao IBGE devido à não adição de óleo na cocção, sendo o óleo presente somente do tempero utilizado no feijão, e devido ao maior rendimento que acaba por diminuir a concentração tanto de lipídeo quanto de sódio?.

Em relação as limitações do estudo, em decorrência do grande volume de informações, não foram apresentadas todos os dados no presente estudo, pois preferiu-se destacar sódio, lipídio e os indicadores culinários. Outra limitação deve-se ao fato de um dia de coleta servir batata palha industrializada como guarnição e por isso não fez-se a FTP, o que por ser industrializada pode aumentar ainda mais o sódio e lipídio do cardápio. Para as entradas fez-se somente o FC, uma vez que os macro e micronutrientes não apresentavam distorções por serem, a maioria, utilizadas in natura.

\section{CONCLUSÃO}

Ao final do trabalho verificou-se a importância da FTP para a padronização de sabor, rendimento e controle de custo da preparação, mas principalmente os valores nutricionais das preparações o que possibilita uma alimentação mais saudável com adequações nutricionais. Isso permite a manutenção de um bom estado nutricional, além de auxiliar na prevenção de DCNT, como hipertensão e dislipidemias.

A FTP também permite identificar pontos negativos da produção, como desperdício e erros na manipulação. Com desse diagnóstico, há possibilidade de corrigi-los e gerar melhor controle dos estoques, logo ter mais lucro, seja na elaboração de lista de compras mais adequada como na responsabilidade ambiental.

Ademais, com a FTP elabora-se o rótulo das preparações, fundamental para que o consumidor conheça os ingredientes e informações nutricionais, gerando maior autonomia e segurança na escolha dos alimentos, bem como servindo como ferramenta para intolerantes ou alérgicos.

Indicações futuras para esta linha de pesquisa devem estar pautadas na modificação de preparações baseadas em ajustes das FTP, visando alcançar redução de sódio, lipídeos, entre outros. Manter o uso da FTP é essencial para qualquer mudança na produção de alimentos e deve ser condição básica para a prática da ciência da nutrição excluindo, assim, o excesso de 
informações disponíveis na mídia e redes sociais, nem sempre adequadas.

\section{REFERÊNCIAS}

1. Akutsu RCCA, Botelho RBA, Camargo EB, Oliveira KESD, Araújo WMC. A ficha técnica de preparação como instrumento de qualidade na produção de refeições. Rev Nutr. 2005; 18(2):277-279.

2. Martins CC. Padronização das preparações de restaurante do tipo self-service [Monografia]. Brasília: Universidade de Brasília; 2003. 66 p.

3. Santos IS, Duarte EC. Fatores de risco e proteção para doenças crônicas não transmissíveis na população adulta brasileira. Rev Saúde Pública. 2009; 43(Supl 2):5-6.

4. Barreto SM, Pinheiro ARDO, Sichieri R, Monteiro CA, Schimidt M I, Lotufo $P$, et al. Análise da estratégia global para alimentação, atividade física e saúde, da Organização Mundial da Saúde. Epidemiol serv saúde. 2005; 14(1):41-68.

5. Araújo WMC, Botelho RBA, Montebello NB, Borgo LA. Alquimia dos Alimentos. Brasília: Editora Senac-DF; 2014.

6. Goes VF, Valduga L, Soares BM. Determinação e Avaliação do Fator de Correção de Hortaliças em uma Unidade de Alimentação e Nutrição de
Guarapuava-PR. UNOPAR Cinet Ciênc Biol Saúde. 2013; 15(ESP):339-42.

7. Lemos AG, Botelho RBA, Akutsu RCCA. Determinação do fator de correção das hortaliças folhosas comercializadas em Brasília. Hortic bras. 2011; 29(2):231-236.

8. Costa V, Rosa MC. Medidas caseiras. Santa Catarina: PET Nutrição/UFSC; 1997.

9. Instituto Brasileiro de Geografia e Estatística. Pesquisa de Orçamentos Familiares 2008-2009 - POF. Rio de Janeiro: IBGE; 2010.

10. Universidade de Campinas. TACO: Tabela Brasileira de Composição dos Alimentos. São Paulo: UNICAMP; 2011.

11. Stubenitsky K, Aaron J, Catt S, Mela D. The influence of recipe modification and nutritional information on restaurant food acceptance and macronutrient intakes. Public Health Nutr. 2000; 3(2):201-9.

12. Ornellas LH. Técnica dietética: seleção e preparo de alimentos. São Paulo: Atheneu; 2007.

13. Benetti GB, Branco LM, Comenale N, Atayde SR, Zollar V. Manual de Técnicas Dietéticas. São Caetano do Sul: Editora Yendis; 2014.

14. Silva SMCS, Bernardes SM. Cardápio guia prático para a elaboração. São Paulo: Atheneu; 2001. 
15. Anjos MCR. Relação de Fatores de Correção e índice de conversão (cocção) de alimentos. Curitiba: Universidade Federal do Paraná; 2012.

16. Proença RPDC. Aspectos organizacionais e inovação tecnológica em processos de transferência de tecnologia: uma abordagem antropotecnológica no setor de alimentação coletiva [tese]. Florianópolis: Universidade Federal de Santa Catarina; 1996. 327 p.

17. Martins CA. Informação alimentar e nutricional de sódio em rótulos de alimentos ultraprocessados prontos e semiprontos para o consumo comercializados no Brasil [tese]. Florianópolis: Universidade Federal de santa Catarina; 2012. 140 p.

18. Denardin CC, Silva LP. Estrutura dos grãos nulos de amido e sua relação com propriedades físicoquímicas. Cienc Rural. 2009; 39(3):945-954.

19. Phillipi ST. Nutrição e técnica dietética. Barueri: Manole; 2004.

20. Frantz $C B$, Veiros $M B$, Proença RPC, Sousa AA. Development of a method for controlling salt and sodium use during meal preparation for food services. Rev Nutr. 2013; 26(1):75-87.

Conflito de interesses: Os autores declaram não haver conflito de interesses.

Participação dos autores:

- Concepção: Pereira IGS, Lemos LW, Lemos KGE, Akutsu RCCA, Botelho RBA, Camargo ÉB.

- Desenvolvimento: Pereira IGS, Lemos LW, Lemos KGE, Akutsu RCCA, Botelho RBA, Camargo ÉB.

- Redação e revisão: Pereira IGS, Lemos LW, Lemos KGE, Akutsu RCCA, Botelho RBA, Camargo ÉB.

Como citar este artigo: Pereira IGS, Lemos LW, Lemos KGE, Akutsu RCCA, Botelho RBA, Camargo ÉB. Construção e implementação de fichas técnicas de preparação de unidade de alimentação e nutrição. J Health NPEPS. 2019; 4(1):210-227. 